\title{
A UNIVERSIDADE FEDERAL DA FRONTEIRA SUL: UMA POLÍTICA PÚBLICA EM PROCESSO DE IMPLEMENTAÇÃO NA PERSPECTIVA DE UMA CONSTRUÇÃO SOCIAL E DE INTERESSES REGIONAIS
}

\author{
THE FEDERAL UNIVERSITY OF SOUTH BORDER: A PUBLIC \\ POLITIC IN IMPLEMENTATION PROCESS IN THE PERSPECTIVE \\ OF A SOCIAL CONSTRUCTION AND REGIONAL INTERESTS
}

\author{
Stefano Moraes Demarco ${ }^{1}$ \\ Claudio Machado Maia ${ }^{2}$
}

\begin{abstract}
RESUMO
Este estudo busca descrever o encadeamento das políticas públicas federais que possibilitaram a expansão das universidades federais, democratizando o acesso ao ensino superior com a possibilidade de interiorização da oferta deste serviço, em especial a Universidade Federal da Fronteira Sul (UFFS). Sendo assim, caracteriza-se a Mesorregião Grande Fronteira do MERCOSUL, criada pela Política Nacional de Desenvolvimento Regional (PNDR), sob critérios do Programa de Promoção da Sustentabilidade de Espaços Sub-Regionais (PROMESO), que visa dirimir as desigualdades regionais, bem como a contextualização da Universidade Federal da Fronteira Sul (UFFS), que tem em sua missão assegurar o acesso à educação superior como fator decisivo para o desenvolvimento, a qualificação profissional e a inclusão social; desenvolver atividades de ensino, pesquisa e extensão buscando a interação e a integração das cidades e estados que compõem a Mesorregião; e promover o desenvolvimento regional integrado - condição essencial para a garantia da permanência dos cidadãos graduados na Mesorregião e a reversão do processo de litoralização hoje em curso.
\end{abstract}

Palavras-chave: Educação superior; Expansão universitária; Mesorregião; UFFS.

\begin{abstract}
This study aims describe the chaining of the federal public policies that allowed the expansion of federal universities, democratizing the access to higher education with the possibility of internalization of supply of this service, in particular the Federal University of South Border (UFFS). This way, is characterized the Great Border Mesoregion of MERCOSUL, created by the National Policies of Regional Development (PNDR), under criteria of the Sustainability Promotion Program of Subregional Spaces (PROMESO), that aims settle the regional inequalities. And the contextualization of the Federal University of South Border (UFFS), that has as a mission ensure the access to higher education as decisive factor for the development, professional qualification and social inclusion; develop educational activities, researches and extension looking for the interaction and integration of cities and states that composes the Mesoregion; and promotes the regional integrated development essential condition to guarantee the permanence of citizens graduated on the Mesoregion and the reversal of the current littoralization process.
\end{abstract}

Keywords: Higher education; University expansion; Mesoregion; UFFS.

\footnotetext{
${ }^{1}$ Universidade Comunitária da Região de Chapecó (UNOCHAPECÓ).

${ }^{2}$ Universidade Comunitária da Região de Chapecó (UNOCHAPECÓ).
} 


\section{Introdução}

A expansão do ensino superior implementada no Brasil, a partir de 2008, através do Programa de Apoio a Planos de Reestruturação e Expansão das Universidades Federais (REUNI) (BRASIL, 2007a), representando uma das ações que integram o Plano de Desenvolvimento da Educação (PDE) (BRASIL, 2007b), que busca ampliar o acesso e a permanência na educação superior, haja vista que a atual oferta de vagas está muito aquém das metas traçadas pelo Plano Nacional de Educação (PNE) ${ }^{3}$ 2001-2010 (BRASIL, 2007b, p. 4).

Com a expansão e interiorização da educação superior pública, a Universidade Federal da Fronteira Sul (UFFS) é concebida com 5 (cinco) Campi, localizados nas cidades de Erechim (RS), Cerro Largo (RS), Laranjeiras do Sul (PR), Realeza (PR) e Chapecó (SC) posteriormente foi implantado o Campus na cidade de Passo Fundo (RS). A preocupação com a democratização do ensino superior, as diversas realidades, a transformação social, atingindo classes sociais historicamente desassistidas e a desconcentração da oferta de Ensino Superior público, demandaram que uma Instituição de Ensino Superior Federal fosse implantada nesta mesorregião.

Nesse contexto, a Universidade Federal da Fronteira Sul (UFFS) é o resultado do encontro das políticas federais com a reivindicação dos movimentos sociais, organizados em torno da ampliação do acesso à educação superior como direito básico e inalienável. $\mathrm{O}$ processo de descentralização da gestão da educação superior coloca possibilidades e desafios que devem ser assumidos de forma solidária. Os diferentes contextos dos municípios e regiões, com as suas particularidades, exigem políticas públicas capazes de responder adequadamente às distintas necessidades advindas dessa diversidade.

A gestão pública, como instrumento de ação política, deve buscar sempre a construção de uma sociedade mais equitativa e democrática (FELICETTI; MOROSINI, 2009, p. 13). Estabelecendo uma política de expansão do ensino superior que contribuía para a diminuição das desigualdades de ofertas entre as diferentes regiões do país (BRASIL, 2001).

Para descrever as informações referentes à política pública que culminou com a implantação dessa nova instituição da Mesorregião Grande Fronteira do MERCOSUL, foi aplicada uma pesquisa exploratória, que proporciona maior familiaridade com o problema, com vistas a torná-lo mais explícito. A utilização desse tipo de pesquisa permite obter novos conhecimentos no campo da realidade social. Esta modalidade contempla a busca de informações na literatura científica e a comparação com a realidade observada (GIL, 2010, p. 27). Como hipóteses condutoras desta reflexão, adotam-se a importância da instalação da Universidade Federal da Fronteira Sul (UFFS) nessa região, assim como a existência da necessidade local para implantação de uma instituição com essas características. Esta pesquisa exploratória empregou os métodos bibliográficos e documentais para atingir os seus objetivos.

\section{Política pública de educação superior}

As ações realizadas pelo Estado, em forma de políticas públicas, visam atender a um somatório de segmentos da sociedade, almejando o bem comum. Deve-se também visualizar

\footnotetext{
${ }^{3}$ Política nacional de expansão da educação superior pública, pela qual o Ministério da Educação (MEC) cumpre o papel atribuído pelo Plano Nacional de Educação (PNE) (Lei nº 10.172/2001).
} 
que o Estado deve planejar a propulsão do desenvolvimento econômico, gerando emprego, renda, tecnologia entre outros benefícios, que, certamente, só poderão ser atingidos com o investimento em educação, nesse caso específico, educação superior.

\begin{abstract}
À União atribui-se historicamente o papel de atuar na educação superior, função prevista na Carta Magna. As instituições públicas deste nível de ensino não podem prescindir do apoio do Estado. As universidades públicas têm um importante papel a desempenhar no sistema, seja na pesquisa básica e na pós-graduação stricto sensu, seja como padrão de referência no ensino de graduação. Além disso, cabe-lhe qualificar os docentes que atuam na educação básica e os docentes da educação superior que atuam em instituições públicas e privadas, para que se atinjam as metas previstas na LDB quanto à titulação docente (BRASIL, 2001).
\end{abstract}

Para imprimir essa característica, desenvolvendo um padrão de qualidade, a União, através do Ministério da Educação, propõe a gestão de uma gama de Instituições de Ensino Superior, que dão a contribuição para a sociedade, formando profissionais qualificados, desenvolvendo tecnologia e, sobretudo, formando cidadãos.

Para tanto, há pelo Governo Federal um aporte cada vez maior de investimento nos serviços da área da educação, nesse caso específico, na educação de nível superior, com a política de expansão do ensino superior e produção de conhecimento. Haja vista que grande parte do tripé da educação - ensino, pesquisa e extensão - é ofertado pelo Estado, como se pode observar pelas diretrizes gerais do plano de reestruturação e expansão das universidades federais que enfatizam a importância da produção do conhecimento nas instituições públicas do país.

Como uma das principais premissas da Lei de Diretrizes e Bases (LDB) de 1996, a União, através do Congresso Nacional, tramitou o Plano Nacional da Educação (PNE), com diretrizes e metas para os dez anos seguintes em consonância com a Declaração Mundial sobre educação para todos. Resultando na homologação da Lei ${ }^{\circ} 10.172$, de 9 de janeiro de 2001, instituindo o Plano Nacional de Educação (PNE), que regulamenta o seguinte objetivo do Ensino Superior:

Criar políticas que facilitem às minorias, vítimas de discriminação, o acesso à educação superior, através de programas de compensação de deficiência de sua formação escolar anterior, permitindo-lhes, desta forma, competir em igualdade de condições nos processos de seleção e admissão a esse nível de ensino (BRASIL, 2001).

A expansão da oferta de ensino superior tem entre os seus objetivos a diminuição das desigualdades existentes entre as diferentes regiões do país. Essa discrepância não é exclusividade entre regiões, mas dentro das esferas estaduais há uma distinção de acesso às universidades federais, que se concentram nos grandes centros urbanos e nas regiões litorâneas, compelindo a uma migração populacional em busca da assistência de uma universidade com essas características, o que poderia representar, muitas vezes, o não retorno desses profissionais ao seu município de origem.

No decorrer da execução deste Plano, foi lançado o Plano de Desenvolvimento da Educação (PDE), que tem como uma das suas ações o Programa de Apoio a Planos de RBPD - Revista Brasileira de Planejamento e Desenvolvimento, v. 2, n. 2, p. 80-93, jul./dez. 2013. 
Reestruturação e Expansão das Universidades Federais (REUNI), que visa ao provimento mínimo da oferta de educação superior para, pelo menos, $30 \%$ dos jovens na faixa etária de 18 a 24 (BRASIL, 2007b, p. 4).

Conforme o Censo da Educação Superior de 2005, o Brasil contava com 176 universidades, das quais 90 eram públicas, sendo 52 do sistema federal, 33 estaduais e 5 municipais. Nesse ano, o sistema público acolhia um total de 1.192.189 matrículas de graduação. O setor privado compreendia 1.934 instituições, dentre elas 86 universidades, com 3.260.967 matrículas de graduação. A cada ano têm ingressado 1.700 .000 novos estudantes de graduação, na modalidade presencial, no sistema nacional de educação superior (INEP, 2005) (BRASIL, 2007b, p. 6).

Desde o início deste novo processo de expansão do ensino superior ocorre uma interiorização das universidades federais. Com isso, o número de municípios atendidos pelas universidades passou de 114, em 2003, para 237, até o fim de 2011. Desde o início da expansão foram criadas 14 novas universidades e mais de 100 novos campi, que possibilitaram a ampliação de vagas e a criação de novos cursos de graduação (REUNI, 2013).

Nesse contexto, a universidade como elemento protagonista no processo propulsor do desenvolvimento assume o papel de impulsionar o incremento intelectual à altura do seu tempo, contribuindo para a construção de uma nova sociedade, pois isso aumenta a oferta de vagas nas Instituições de Ensino Superior, promove a inclusão social, zela pela qualidade da Educação e oportuniza, em especial aos alunos com "características especiais", uma nova perspectiva de vida, além de possibilidades de mobilidade social (FELICETTI; MOROSINI, 2009, p.15).

A despeito do Programa de Apoio a Planos de Reestruturação e Expansão das Universidades Federais (REUNI) prever a expansão e, consequentemente, a interiorização das universidades federais, a Universidade Federal da Fronteira Sul (UFFS), escopo desta pesquisa, não se encontra contemplada por esse programa, mas surgiu devido a essas características, pois representa os mesmos ideais.

\section{A Mesorregião Grande Fronteira do Mercosul}

O Brasil, um país com dimensões continentais, é reconhecido por sua diversidade geográfica, étnica e cultural, mas, sobretudo, por uma diversidade social e econômica preocupantes, dados os indicadores de concentração de renda e desigualdades regionais que ainda se apresentam como desafios à sociedade brasileira na mitigação dessas diferenças. Sendo assim, concebida pelo Ministério da Integração Nacional, foi implantada a Política Nacional de Desenvolvimento Regional (PNDR), para proporcionar ferramentas e instrumentos para o desenvolvimento regional, com uma inserção social e econômica, valorizando o potencial endógeno de uma determinada mesorregião para obter impactos sociais e, de modo geral, importância no cenário nacional (BRASIL, 2009, p. 5).

Seguindo as diretrizes da Política Nacional de Desenvolvimento Regional (PNDR), que visa dirimir substancialmente as desigualdades regionais, foi implementado o Programa de Promoção da Sustentabilidade de Espaços Sub-Regionais (PROMESO), com o intuito reafirmar os potenciais endógenos das mesorregiões diferenciadas. 
O Programa de Promoção da Sustentabilidade de Espaços Sub-Regionais (PROMESO) orienta-se pelas diretrizes da Política Nacional de Desenvolvimento Regional (PNDR), que busca a redução das desigualdades regionais e atua a partir de dois eixos principais: a organização social e a ativação econômica. O primeiro eixo volta-se ao estímulo e fortalecimento dos fóruns mesorregionais para que sejam canais de participação da sociedade civil na definição de ações a serem contempladas com investimentos públicos. O eixo da ativação econômica se dá por meio do fomento aos Arranjos Produtivos Locais identificados como prioritários nas Mesorregiões Diferenciadas e nas Regiões Integradas de Desenvolvimento RIDEs (BRASIL, 2009, p. 10).

Em sintonia com a Política Nacional de Desenvolvimento Regional (PNDR), cuja escala prioritária é a mesorregional, os espaços sub-regionais contemplados pelo Programa de Promoção da Sustentabilidade de Espaços Sub-Regionais (PROMESO) incluem as Mesorregiões Diferenciadas - caso específico da Mesorregião Grande Fronteira do MERCOSUL. As Mesorregiões Diferenciadas são espaços contínuos, formados por territórios de uma ou mais Unidades da Federação, o que as tornam distintas das mesorregiões adotadas pelo Instituto Brasileiro de Geografia e Estatística (IBGE), que são desenhadas como base nas fronteiras estaduais. Embora possam abranger territórios de mais de um estado, as Mesorregiões Diferenciadas são menores que as Macrorregiões determinadas IBGE. Como consequência, as Mesorregiões Diferenciadas são formadas por territórios e municípios que apresentam identidades físicas, econômicas, sociais e culturais e permitem a configuração de um arranjo político-institucional com participação da sociedade civil, num processo de busca de coordenação e efetividade das ações territoriais das políticas públicas de diferentes esferas de poder. Com o intuito de contribuir para a redução das desigualdades regionais e para a promoção de dinâmicas mais inclusivas de desenvolvimento, esse arranjo políticoinstitucional tem o papel de definir de forma participativa os objetivos específicos e identificar as potencialidades a serem fortalecidas e as vulnerabilidades a serem dirimidas. A ênfase inicial foi dada, a partir da necessidade de organização e de capacitação da sociedade nesses espaços para o encaminhamento de suas demandas, aproveitando toda a experiência acumulada pelas sub-regiões brasileiras (BRASIL, 2009, p. 10).

Com estas prerrogativas, surgiu a Mesorregião Grande Fronteira do Mercosul, através da criação do Fórum de Desenvolvimento Integrado e Sustentável da Mesorregião da Grande Fronteira do Mercosul, com os principais projetos, tais como de fortalecimento de agroindústrias familiares; desenvolvimento do Arranjo Produtivo Local (APL) de móveis; sinalização turística na região das missões jesuíticas; fortalecimento da piscicultura; fortalecimento da viticultura; lapidação e artesanato mineral; e apoio ao setor lácteo (BRASIL, 2014, p. 1). Tendo como propósito reduzir as desigualdades regionais e ativar os potenciais de desenvolvimento dessa região, explorando as particularidades locais (BRASIL, 2014, p. 1-2).

A Mesorregião Grande Fronteira do MERCOSUL é composta pelo sudoeste do Paraná, oeste de Santa Catarina e o norte do Rio Grande do Sul, abrangendo 396 municípios, sendo 223 no norte do Rio Grande do Sul, 131 no oeste de Santa Catarina e 42 no sudoeste do Paraná, com área total estimada de 139 mil quilômetros quadrados e população de aproximadamente 4 milhões de habitantes. A despeito de esta mesorregião ter uma ocupação considerada antiga, o seu contingente de urbanização é relativamente baixo em comparação com o resto do país, em torno de $65 \%$, sendo que apresenta uma parcela significativa da

RBPD - Revista Brasileira de Planejamento e Desenvolvimento, v. 2, n. 2, p. 80-93, jul./dez. 2013. 
população na zona rural (MESOMERCOSUL, 2013). A Figura 1 ilustra os limites geográficos da Mesorregião Grande Fronteira do Mercosul.

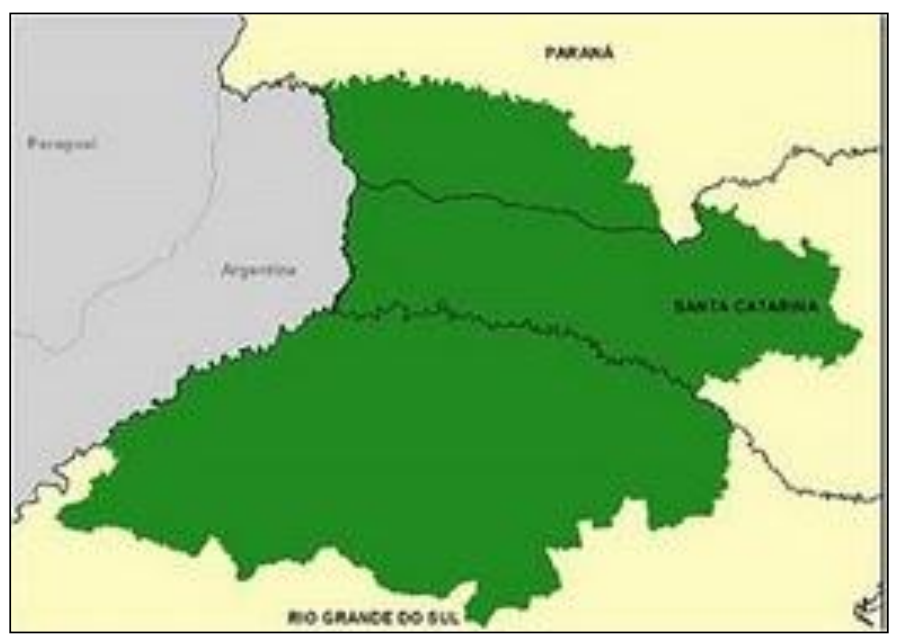

Figura 1 - A Mesorregião Grande Fronteira do Mercosul

Fonte: GT de criação da Universidade Federal da Fronteira Sul.

Para Damo (2006, p. 97), a mesorregião possui identidade histórica própria, forjada desde a chegada dos imigrantes à Região Sul, sobretudo ao Rio Grande do Sul, quando houve necessidade de as famílias agirem em conjunto, a favor de interesses individuais e coletivos. Outro fator determinante na identidade mesorregional é a inserção nas bacias hidrográficas do Rio Uruguai (contemplando municípios gaúchos e catarinenses) e do Rio Paraná (contemplando municípios paranaenses), com semelhanças físicas e socioeconômicas que reforçam sua identidade histórica e cultural (SOLDI et al., 2007, p. 17-18).

Para o seu desenvolvimento, a mesorregião apresenta tradição do associativismo, entretanto destacam-se alguns entraves para o crescimento, tais como: a grande dificuldade de os municípios pequenos, isoladamente, terem acesso a recursos financeiros e humanos qualificados; a escassez de recursos voltados para o desenvolvimento das regiões; a necessidade de uma gestão eficiente que potencialize os recursos disponíveis; a crescente perda de dinamismo da economia regional quanto ao contexto de globalização e competitividade; a dificuldade de inserção da pequena propriedade rural no mercado e as precárias condições de moradia de significativa parcela da população, com deficiências de saneamento básico, acesso à saúde e educação. Como consequência dos fatores elencados, advém a baixa capacidade de absorção de mão de obra e a retenção da população, gerando êxodo rural e emigração regional (MESOMERCOSUL, 2013).

Dessa forma, a implantação de uma universidade federal configura-se como um programa público de relevância, pois é fator importante para a formação de capital social e geração de ciência e tecnologia, impactando no processo de desenvolvimento mesorregional (SOLDI et al., 2007, p. 19).

\section{A Universidade Federal da Fronteira Sul}

Há uma conscientização do papel preponderante das universidades no desenvolvimento regional e na descentralização da produção do conhecimento, e nesse caso específico, na descentralização do acesso ao ensino superior, a uma instituição pública 
federal. Seus impactos vão além da rede de alunos assistidos, pois suas externalidades positivas alcançadas com ensino, pesquisa e extensão não podem ser mensuradas, além do fato de que a Universidade Federal da Fronteira Sul (UFFS) foi concebida com características populares, disposta a atender a uma camada social que não tinha acesso a uma universidade federal.

As universidades federais mais próximas advindas do Rio Grande do Sul são a Universidade Federal do Rio Grande do Sul (UFRGS) e a Universidade Federal de Santa Maria (UFSM), localizadas, respectivamente, em Porto Alegre e Santa Maria, cidades a aproximadamente $400 \mathrm{~km}$ de Erechim (RS). Em Santa Catarina, havia uma única universidade federal, a Universidade Federal de Santa Catarina (UFSC), localizada aproximadamente a $540 \mathrm{~km}$ de Chapecó (SC), enquanto que no Paraná, a Universidade Federal do Paraná (UFPR), instalada em Curitiba, está aproximadamente a $370 \mathrm{~km}$ de Laranjeiras do Sul (PR).

Acrescente-se que, pelas peculiaridades da Mesorregião Grande Fronteira do Mercosul, preponderantemente habitada e concentrada economicamente na agricultura familiar, desenvolvida no modelo minifundiário, a saída dos jovens para avançar nos estudos em instituições de ensino superior federal e busca de qualificação, auferindo novos conhecimentos e tecnologias, sempre envolviam custos de manutenção insuportáveis para esse modelo de economia.

Justamente esses que poderiam dar continuidade, com ganhos significativos, mantendo os valores e todo o arcabouço sociocultural de uma base territorial ávida para mostrar sua capacidade de desenvolvimento, sempre com vontade de mostrar afastamento da acomodação e avessa a ver seus valores debandados por falta de oportunidade de exercê-los no próprio meio.

Pelo fato de, historicamente, as universidades federais se concentrarem nos grandes polos urbanos e nas regiões litorâneas do território nacional, em determinadas áreas havia falta de profissionais qualificados para exercerem relevantes funções sociais. Portanto, há noção da importância, da orientação e da finalidade do conhecimento, pela sociedade, como agente transformador, que proporciona empoderamento e se traduz em uma porta de entrada para o mercado de trabalho.

A Universidade Federal da Fronteira Sul (UFFS) é uma instituição de ensino superior pública e popular. Criada pela Lei $\mathrm{n}^{\circ} 12.029$, de 15 de setembro de 2009, abrange os 396 municípios da Mesorregião Grande Fronteira Mercosul - sudoeste do Paraná, oeste de Santa Catarina e noroeste do Rio Grande do Sul. Foi constituída com cinco campi: Chapecó (SC), sede da instituição; Realeza e Laranjeiras do Sul (PR); Cerro Largo e Erechim (RS), no ano de 2013, foi implantado o campus na cidade de Passo Fundo (RS), ofertando o curso de Medicina. Suas atividades acadêmicas se iniciaram com a proposta de 33 cursos, para os quais haveria 42 turmas ingressantes anualmente. A universidade prevê 10 mil alunos nos primeiros cinco anos. Os cursos de graduação oferecidos privilegiam as vocações da economia regional - visando ao desenvolvimento regional integrado, pela valorização e superação da matriz produtiva - e estão em consonância com a Política Nacional de Formação de Professores do Ministério da Educação (MEC) (UFFS, 2012).

Portanto, a Universidade Federal da Fronteira Sul (UFFS) é uma autarquia vinculada ao Ministério da Educação (MEC), com autonomia didática científica, administrativa, de gestão patrimonial e financeira, nos termos da Lei de sua criação e de seu Estatuto. Tem a missão de assegurar o acesso à educação superior como fator decisivo para o desenvolvimento da Mesorregião Grande Fronteira do Mercosul, a qualificação profissional e 
a inclusão social; desenvolver atividades de ensino, pesquisa e extensão, buscando a interação e a integração das cidades e estados que compõem a Grande Fronteira do MERCOSUL e seu entorno; promover o desenvolvimento regional integrado - condição essencial para a garantia da permanência dos cidadãos graduados na Mesorregião Grande Fronteira do Mercosul e a reversão do processo de litoralização hoje em curso.

Para alcançar a missão traçada, a instituição cunhou como característica ser uma universidade pública e popular, de qualidade, comprometida com a formação de cidadãos conscientes e com o desenvolvimento sustentável e solidário da Região Sul do país, além de democrática, autônoma, que respeita a pluralidade de pensamento e a diversidade cultural, com garantia de espaços de participação dos diferentes atores sociais, e para isso deve estabelecer dispositivos de combate às desigualdades sociais e regionais - incluindo condições de acesso e permanência no ensino superior, especialmente da população mais excluída do campo e da cidade -, tendo na agricultura familiar um setor estruturado e dinamizador que tenha como premissa a valorização e a superação da matriz produtiva do país (UFFS, 2012).

E para assistir essa demanda de estudantes egressos do ensino médio e concretizar a política pública implementada, foi alocado, a despeito de um planejamento para pesquisa e extensão, distribuídos nos campi da Universidade Federal da Fronteira Sul (UFFS), vinte cursos de graduação nas modalidades de Licenciatura e Bacharelado. No Quadro 1, verificase os cursos ofertados na Modalidade de Bacharelado.

Quadro 1 - Cursos Ofertados na Modalidade de Bacharelado

\begin{tabular}{|c|c|c|c|c|}
\hline Curso & $\begin{array}{c}\text { Carga } \\
\text { horária }\end{array}$ & Duração & $\begin{array}{l}\text { Vagas } \\
\text { anuais }\end{array}$ & Campus \\
\hline Administração & 3.270 horas & $\begin{array}{l}09 \text { semestres }- \text { período diurno } \\
10 \text { semestres - período noturno }\end{array}$ & 100 & Chapecó \\
\hline Administração & 3.390 horas & 08 semestres - período integral & 55 & Cerro Largo \\
\hline $\begin{array}{l}\text { Arquitetura e } \\
\text { Urbanismo }\end{array}$ & 4.020 horas & 10 semestres - período integral & 50 & Erechim \\
\hline $\begin{array}{l}\text { Agronomia } \\
\text { (Ếnfase em } \\
\text { Agroecologia) }\end{array}$ & 4.515 horas & 10 semestres - período integral & 200 & $\begin{array}{l}\text { Cerro Largo (50 vagas) } \\
\text { Erechim ( } 50 \text { vagas) } \\
\text { Laranjeiras do Sul ( } 50 \\
\text { vagas) } \\
\text { Chapecó (50 vagas) }\end{array}$ \\
\hline $\begin{array}{l}\text { Ciências da } \\
\text { Computação }\end{array}$ & 3.090 horas & $\begin{array}{l}08 \text { semestres - período matutino } \\
10 \text { semestres - período noturno }\end{array}$ & 100 & Chapecó \\
\hline $\begin{array}{l}\text { Ciências } \\
\text { Econômicas }\end{array}$ & 3.330 horas & $\begin{array}{l}08 \text { semestres - período matutino } \\
09 \text { semestres - período noturno }\end{array}$ & 58 & Laranjeiras do Sul \\
\hline Enfermagem & 4.395 horas & 10 semestres - período integral & 40 & Chapecó \\
\hline $\begin{array}{l}\text { Engenharia } \\
\text { Ambiental e } \\
\text { Energias } \\
\text { Renováveis }\end{array}$ & 4.230 horas & 10 semestres - período integral & 150 & $\begin{array}{l}\text { Cerro Largo ( } 50 \text { vagas) } \\
\text { Chapecó (50 vagas) } \\
\text { Erechim (50 vagas) }\end{array}$ \\
\hline $\begin{array}{l}\text { Engenharia de } \\
\text { Alimentos }\end{array}$ & 4.470 horas & 11 semestres - período integral & 50 & Laranjeiras do Sul \\
\hline $\begin{array}{l}\text { Engenharia de } \\
\text { Aquicultura }\end{array}$ & 3.765 horas & 10 semestres - período integral & 50 & Laranjeiras do Sul \\
\hline Nutrição & 3.990 horas & 10 semestres - período integral & 40 & Realeza \\
\hline $\begin{array}{l}\text { Medicina } \\
\text { Veterinária }\end{array}$ & 4.860 horas & 11 semestres - período integral & 50 & Realeza \\
\hline
\end{tabular}

Fonte: UFFS (2012, p. 59-60). 
Sendo assim, dentro dos princípios sólidos da Universidade Federal da Fronteira Sul (UFFS), oferta-se uma formação voltada ao mercado de trabalho, habilitando o Bacharel a exercer atividade profissional em sua área de conhecimento, visando ao desenvolvimento agregado da região oeste de Santa Catarina, sudoeste do Paraná e noroeste do Rio Grande do Sul.

No ano de 2013, foi agregado aos Cursos da Modalidade de Bacharelado, o Curso de Medicina, no campus Passo Fundo (RS), ofertando 40 vagas, com entrada anual, turno integral e carga horária total de 8.280 horas (BRASIL, 2012, p. 51).

A oferta de cursos na Modalidade de Licenciatura vem ao encontro dos objetivos estipulados pelo Plano Nacional da Educação (PNE), Plano de Desenvolvimento da Educação (PDE) e o Programa de Apoio a Planos de Reestruturação e Expansão das Universidades Federais (REUNI), que convergem com o objetivo de ampliar a oferta de vagas de Cursos de Licenciatura, com vistas a aprimorar a formação acadêmica do professor, para sua qualificação no magistério. Para tanto, distribuídos em todos os seus campi, com exceção do campus Passo Fundo (RS), a Universidade Federal da Fronteira Sul (UFFS) disponibiliza o montante de 1.230 vagas de formação específica de nível superior em Licenciatura. No Quadro 2, verifica-se os cursos ofertados na Modalidade de Licenciatura.

Quadro 2 - Cursos ofertados na Modalidade de Licenciatura

\begin{tabular}{|c|c|c|c|c|}
\hline Curso & Carga horária & Duração & $\begin{array}{c}\text { Vagas } \\
\text { anuais }\end{array}$ & Campus \\
\hline $\begin{array}{l}\text { Ciências: Biologia, } \\
\text { Física e Química }\end{array}$ & 4.770 horas & $\begin{array}{l}11 \text { semestres no } \\
\text { período noturno }\end{array}$ & 300 & $\begin{array}{l}\text { Realeza (150 vagas) } \\
\text { Cerro Largo ( } 150 \text { vagas) }\end{array}$ \\
\hline $\begin{array}{l}\text { Interdisciplinar } \\
\text { em Educação no } \\
\text { Campo }\end{array}$ & 3.405 horas & $\begin{array}{l}09 \text { semestres em } \\
\text { período diurno e } \\
\text { noturno }\end{array}$ & 60 & Laranjeiras do Sul \\
\hline Filosofia & 3.075 horas & $\begin{array}{l}08 \text { semestres no } \\
\text { período matutino } \\
09 \text { semestres no } \\
\text { período noturno }\end{array}$ & 150 & $\begin{array}{l}\text { Chapecó (100 vagas) } \\
\text { Erechim ( } 50 \text { vagas) }\end{array}$ \\
\hline História & 3.030 horas & $\begin{array}{l}09 \text { semestres no } \\
\text { período matutino } \\
10 \text { semestres no } \\
\text { período noturno }\end{array}$ & 150 & $\begin{array}{l}\text { Chapecó (100 vagas) } \\
\text { Erechim ( } 50 \text { vagas) }\end{array}$ \\
\hline Geografia & 3.225 horas & $\begin{array}{l}08 \text { semestres no } \\
\text { período matutino } \\
09 \text { semestres no } \\
\text { período noturno }\end{array}$ & 150 & $\begin{array}{l}\text { Chapecó (100 vagas) } \\
\text { Erechim ( } 50 \text { vagas) }\end{array}$ \\
\hline Ciências Sociais & 3.285 horas & $\begin{array}{l}08 \text { semestres no } \\
\text { período matutino } \\
09 \text { semestres no } \\
\text { período noturno }\end{array}$ & 150 & $\begin{array}{l}\text { Chapecó (100 vagas) } \\
\text { Erechim ( } 50 \text { vagas) }\end{array}$ \\
\hline Pedagogia & 3.375 horas & $\begin{array}{l}09 \text { semestres no } \\
\text { período matutino } \\
10 \text { semestres no } \\
\text { período noturno }\end{array}$ & 150 & $\begin{array}{l}\text { Chapecó (100 vagas) } \\
\text { Erechim ( } 50 \text { vagas) }\end{array}$ \\
\hline $\begin{array}{l}\text { Letras: Português } \\
\text { e Espanhol }\end{array}$ & 3.855 horas & $\begin{array}{l}09 \text { semestres no } \\
\text { período matutino } \\
10 \text { semestres no } \\
\text { período noturno }\end{array}$ & 120 & $\begin{array}{l}\text { Cerro Largo (30 vagas) } \\
\text { Chapecó (60 vagas) } \\
\text { Realeza (30 vagas) }\end{array}$ \\
\hline
\end{tabular}

Fonte: UFFS (2012, p. 60).

RBPD - Revista Brasileira de Planejamento e Desenvolvimento, v. 2, n. 2, p. 80-93, jul./dez. 2013. 
Com a Licenciatura, além da formação plena, tem-se o objetivo de preparar o estudante para a transmissão do conhecimento e para uma formação qualificada, além de conseguir manter os profissionais na Mesorregião Grande Fronteira do Mercosul, por não haver necessidade de deslocamento durante o período da Graduação, gerando assim a oferta de novos docentes na educação básica, proporcionando educação com qualidade.

Tanto os cursos da Modalidade Bacharelado quanto os da Modalidade Licenciatura são organizados por meio de uma matriz curricular compreendida em três áreas: Domínio Comum, Domínio Conexo e Domínio Específico; e tem por objetivo assegurar que todos os estudantes recebam formação cidadã, interdisciplinar e profissional, estreitando as relações entre a comunidade acadêmica e a sociedade.

Consubstanciada por seus objetivos e metas, comprometida com a formação técnica e ética de cidadãos e com o desenvolvimento sustentável e solidário da Mesorregião, a Universidade busca ser referência no combate às desigualdades sociais, proporcionando condições de acesso e permanência no ensino superior, não se esquecendo de suas origens, ou seja, de seu retorno a uma agricultura familiar estruturada e dinamizada, visando ao desenvolvimento da matriz produtiva regional (ALMEIDA JÚNIOR; TOSTA, 2011, p. 30).

Agregado aos cursos de graduação, a Universidade Federal da Fronteira Sul (UFFS) oferta ensino em cursos de Pós-Graduação nas modalidades lato sensu - Epistemologia e Metafísica, Produção de Leite Agroecológico, Desenvolvimento Rural Sustentável e Agricultura Familiar, Teorias Linguísticas Contemporâneas, Ensino de Língua e Literatura, Ensino de Ciências e Matemática, Interdisciplinaridade e Práticas Pedagógicas na Educação Básica, História Regional, Literaturas do Cone Sul, Saúde Coletiva, História da Ciência, Processos Pedagógicos da Educação Básica, Orientação Educacional, Educação Integral - e stricto sensu. No ano de 2013, foram ofertados dois programas em nível de MestradoAcadêmico: Pós-Graduação em Estudos Linguísticos e Mestrado em Educação.

Além da capacidade de transformar alunos em profissionais com nível superior, fomentando o desenvolvimento mesorregional e agindo no estímulo de ascensão social, a Universidade Federal da Fronteira Sul (UFFS) investe em projetos de pesquisa e de extensão, agregando um componente intangível na capacidade de diversificação do conhecimento, o que poderá, a médio prazo, impactar nos rumos para o incremento social.

Para ofertar essa diversidade de cursos de graduação e pós-graduação e abrigar a comunidade acadêmica até o ano de 2013, conforme dados do Serviço de Informação ao Cidadão (SIC), foi investido em infraestrutura o montante $\mathrm{R} \$ 140.226 .903,84$ (cento e quarenta milhões, duzentos e vinte seis mil, novecentos e três reais e oitenta e quatro centavos), dividido por cidade contemplada com campus, conforme pode ser observado no Quadro 3:

Quadro 3 - Investimento Financeiro em Infraestrutura

\begin{tabular}{|l|l|}
\hline Campus & Valor $(\mathbf{R} \$ \mathbf{)}$ \\
\hline Chapecó & $42.897 .010,57$ \\
\hline Erechim & $22.177 .186,27$ \\
\hline Cerro Largo & $23.351 .191,50$ \\
\hline Laranjeiras do Sul & $27.209 .627,43$ \\
\hline Realeza & $24.591 .888,07$ \\
\hline TOTAL & $\mathbf{1 4 0 . 2 2 6 . 9 0 3 , 8 4}$ \\
\hline
\end{tabular}

Fonte: Serviço de Informação ao Cidadão (SIC). 
O total desses recursos visa assegurar a adequação física para o funcionamento das atividades pedagógicas e administrativas, sendo assim, possibilita o desenvolvimento do ensino, da pesquisa e da extensão.

Compondo essa estrutura organizativa, há uma equipe, entre Professores e Técnicos Administrativos Educacionais, formada por 983 servidores especializados em diversas áreas de conhecimento, que foram contratados por meio de concurso público e estão distribuídos entre a Reitoria e os seis campi. Por outro lado, o contingente de alunos no ano de 2013 é de 6.410 alunos, matriculados nos diversos cursos ofertados, sendo que, 93,70\% dos alunos com vínculo na instituição são oriundos de escola pública.

Com a implantação da Universidade Federal da Fronteira Sul (UFFS), foi proposta uma mudança no processo de desenvolvimento local, uma mudança estrutural na Mesorregião Grande Fronteira do Mercosul, buscando manter e capacitar os jovens a tomar decisões com propriedade, que melhor direcionem os rumos dessa sociedade.

A busca pela inclusão social pode ser afirmada com o sistema diferenciado de cotas para o ingresso, beneficiando os alunos oriundos das escolas públicas, dando continuidade à formação da Rede Pública de Ensino Médio, agregado, as reservas de vagas para os autodeclarados pretos, pardos e indígenas, e a instituição de um programa de apoio financeiro e pedagógico ao estudante, com a criação de bolsas e auxílios, procurando diminuir os índices de evasão e possibilitando ao estudante maior dedicação às atividades acadêmicas.

Entretanto, por ser uma Instituição de Ensino Superior que recentemente entrou em funcionamento e ainda não formou a primeira turma, é incipiente mensurar os impactos e as externalidades positivas que a implantação da Universidade Federal da Fronteira Sul (UFFS) possa vir a causar a Mesorregião Grande Fronteira do Mercosul. Contudo, a quantidade de estudantes que estão sendo atendidos e os que terão acesso a uma instituição de ensino superior público federal, que de outra forma não o teriam, proporcionará um contingente de profissionais especializados, cuja presença, se forem retidos nessa Mesorregião, poderá significar uma oportunidade de dinamização econômica e social, impulsionando um mecanismo de desenvolvimento endógeno, como processo de ampliação do bem-estar da população.

\section{Considerações finais}

A Universidade Federal da Fronteira Sul (UFFS) foi estabelecida com a finalidade de abranger os 396 municípios da Mesorregião Grande Fronteira do MERCOSUL e a tríade missão de assegurar $\mathrm{o}$ acesso à educação superior como fator decisivo para $\mathrm{o}$ desenvolvimento mesorregional, a qualificação profissional e a inclusão social; desenvolver atividades de ensino, pesquisa e extensão buscando a interação e a integração das cidades e estados que compõem a mesorregião e seu entorno; e promover o desenvolvimento regional integrado - condição essencial para a tentativa de manter os cidadãos graduados na mesorregião e a reversão do processo que tem caracterizado a dinâmica que envolve pessoas em busca de estudo em muitas Instituições de Ensino Superior Federal (UFFS, 2013). Aliado ao fato de ser uma universidade pública e popular, planejada através das inspirações dos movimentos sociais.

A ampliação da oferta de ensino superior beneficiou diretamente os cidadãos da Mesorregião Grande Fronteira do Mercosul. Mesorregião concebida pela Política Nacional de

RBPD - Revista Brasileira de Planejamento e Desenvolvimento, v. 2, n. 2, p. 80-93, jul./dez. 2013. 
Desenvolvimento Regional (PNDR), sob critérios do Programa de Promoção da Sustentabilidade de Espaços Sub-Regionais (PROMESO), neste caso específico por meio do Fórum de Desenvolvimento Integrado e Sustentável da Mesorregião da Grande Fronteira do Mercosul, abrangendo 396 municípios, sendo 223 no norte do Rio Grande do Sul, 131 no oeste de Santa Catarina e 42 no sudoeste do Paraná.

Assim sendo, na sua concepção e etapas iniciais de uma política pública, cujo objetivo basilar é a contribuição para a transformação de uma região do país, apresenta-se como realidade, uma vez que a demanda pelo ensino superior foi atendida e estão sendo desenvolvidas pesquisa e extensão. Os resultados da implantação dessa Instituição de ensino superior são perceptíveis, porém seus impactos, pela precocidade da intervenção, ainda não podem ser mensurados, pois as primeiras turmas não foram formadas. Contudo, a Instituição foi implantada, está em desenvolvimento, possui sedes, corpo diretivo, administrativo, pedagógico e de ensino, pesquisa e extensão. E, a sociedade, como usuária e público-alvo, beneficia-se de sua presença. Recursos são transferidos e investidos, continuadamente, assim como uma gama significativa de jovens, que seguramente estariam excluídos do processo universitário federal, mas já frequentam as salas de aula em cursos ofertados de acordo com as demandas e características peculiares de cada região, proporcionando um maior empoderamento local.

A expectativa acerca do desenvolvimento regional sustentável que recai sobre os resultados gerados pela implantação da Universidade Federal da Fronteira Sul (UFFS) é extremamente grande, pois a sua implantação foi reivindicada pela sociedade. Assim como todo um acumulado histórico de desigualdades perante o desenvolvimento da mesorregião em relação a outras que obtiveram recursos anteriormente passam a se fazer presentes nas reivindicações populares. Diante dos fatores históricos que compreenderam a colonização da Mesorregião Grande Fronteira do Mercosul e sua trajetória de desenvolvimento até os dias atuais, podem-se aglutinar as diversas vicissitudes pelas quais passou toda a população compreendida, as perspectivas de novas conjunturas para o desenvolvimento, proporcionadas pela implantação de uma Universidade Federal, bem como os novos desafios que a Instituição terá de cumprir nessa região.

A estruturação da nova universidade em seis campi, distribuídos pela Mesorregião Grande Fronteira do Mercosul, busca atender à meta de oferta e presença da Educação Superior Pública Federal nesta Mesorregião, possibilitando uma alternativa transformadora e propulsora no processo de desenvolvimento, com atendimento de algumas das demandas buscadas por sua comunidade, no sentimento individual e de sociedade organizada, assim como a possibilidade de fixação no território daquela parte da sua população que viesse a buscar qualificação superior noutras localidades; do aumento do pertencimento; melhoria dos índices de satisfação coletiva; perspectiva de crescimento dos indicadores de desenvolvimento humano. Sendo assim, a universidade como um dos elementos indutores de um processo de desenvolvimento para o aumento da especialização produtiva traz uma alternativa local ao processo de mudança nas dinâmicas regionais, possibilitando maior interação e empoderamento do capital social, transferência do conhecimento e oportunidade inovadora intracomunidade.

A escolha das sedes e alocação dos cursos de licenciamento e graduação atende à demanda de cada entorno, como também preserva e valoriza a vocação natural e necessidades de cada base territorial. Assegurando, deste modo, a perspectiva da utilidade e da contribuição positiva, como serviço público, aos diversos alvos e segmentos que compõem o estrato humano, social e econômico do campo de abrangência. A implementação executada, que vai 
diretamente, com a perspectiva de alcance dos melhores resultados, ao atendimento das expectativas iniciais dos setores envolvidos, faz parte da política pública de educação superior, presente no nascimento e implantação desta Universidade - a priorização do aluno egresso da escola pública e adoção de políticas afirmativas.

Silva Filho e Carvalho (2001, p. 471) afirmam que, para haver crescimento, é necessária que haja inovação tecnológica endógena, capital humano, política governamental, agregado, ao papel fundamental da sociedade civil organizada. Esse somatório de premissas vem ao encontro da política pública implementada de expansão das Instituições de Ensino Superior, visando à modificação dos cenários de cada região contemplada.

O desenvolvimento de uma nação perpassa, obrigatoriamente, o aperfeiçoamento do sistema de educação superior, resultando no investindo em ensino, pesquisa e extensão, para a formação de profissionais qualificados e atendimento a toda uma sociedade, o que é ainda mais representativo em uma mesorregião que não possuía uma assistência de ensino superior do governo federal em relação a uma instituição com essas características.

\section{REFERÊNCIAS}

ALMEIDA JÚNIOR, Vicente de Paula; TOSTA, Kelly Cristina Benetti Tonani. Universidade pública, democrática e popular: os desafios da implantação da Universidade Federal da Fronteira Sul. Revista Gestão Universitária na América Latina, Florianópolis, Edição Especial, p. 25-36, 2011.

BRASIL. Constituição da República Federativa do Brasil.1988. Disponível em: <http://www.planalto.gov.br/ccivil_03/constituicao/Constituicao.htm>. Acesso em: 10 jan. 2014.

Lei $n^{\circ}$ 9.394, de 20 de dezembro de 1996. Lei de Diretrizes e Bases da Educação Nacional. Estabelece as diretrizes e bases da educação nacional. Diário Oficial [da] República Federativa do Brasil, Poder Legislativo, Brasília, DF, 23 dez. 1996. p. 27833. Disponível em: <http://www6.senado.gov.br/legislacao/ListaTextoIntegral.action?id=75723>. Acesso em: 15jan. 2014.

. Lei ${ }^{\circ} 10.172$, de 9 de janeiro de 2001. Aprova o Plano Nacional de Educação e dá outras providências. Diário Oficial da União, Poder Legislativo, Brasília, DF, 10 jan. 2001. Disponível em: <http://www6.senado.gov.br/legislacao/ListaPublicacoes.action?id=231634>. Acesso em: 16 jan. 2014.

Decreto Presidencial n ${ }^{\circ}$ 6.096, de 24 de abril de 2007. Institui o Programa de Apoio a Planos de Reestruturação e Expansão das Universidades Federais - REUNI. Diário Oficial da União, Poder Legislativo, Brasília, DF, 25 abr. 2007a. Disponível em: <http://www.planalto.gov.br/ccivil_03/_ato2007-2010/2007/decreto/d6096.htm>. Acesso em: 20 jan. 2014.

Ministério da Educação. O Plano de desenvolvimento da educação: razões, princípios e programas. Brasília: MEC, $2007 \mathrm{~b}$.

Ministério da Integração Nacional. PROMESO: Programa de Promoção da Sustentabilidade de Espaços Sub-Regionais. Brasília: Ministério da Integração Nacional, 2009.

RBPD - Revista Brasileira de Planejamento e Desenvolvimento, v. 2, n. 2, p. 80-93, jul./dez. 2013. 
Lei $\mathrm{n}^{\mathrm{o}}$ 12.029, de 15 de setembro de 2009. Institui a Universidade Federal da Fronteira Sul - UFFS. Diário Oficial da União, Poder Legislativo, Brasília, DF, 16 set. 2009. Disponível em: <http://www.planalto.gov.br/ccivil_03/_ato20072010/2009/Lei/L12029.htm>. Acesso em: 3 jan. 2014.

Ministério da Educação. Projeto do Campus Passo Fundo - RS: Projeto Pedagógico do Curso de Medicina. Chapecó: Universidade Federal da Fronteira Sul, 2012.

Ministério da Integração Nacional. Secretaria de Programas Regionais. Disponível

em:

<http://www.mi.gov.br/programas/programasregionais/index.asp?area=spr_mes_fronteira $>$. Acesso em: 10 jan. 2014.

COSTA, Alexandre Marino Costa et al. Aspectos da reestruturação das universidades federais por meio do REUNI: um estudo do estado de Santa Catarina. Revista Gestão Universitária na América Latina, Florianópolis, Edição Especial, p. 01-24, 2011.

DAMO, Marcia Regina Sartori. Análise da descentralização administrativa do governo do estado e os efeitos da fragmentação territorial no oeste catarinense. Florianópolis: UFSC, 2006.

FELICETTI, Vera Lucia; MOROSINI, Marília Costa. Equidade e iniquidade no ensino superior: uma reflexão. Revista Ensaio: avaliação e políticas públicas em educação, Rio de Janeiro, v. 17, n. 62, p. 9-24, jan./mar. 2009.

GIL, Antônio Carlos. Como Elaborar Projetos de Pesquisa. 5. ed. São Paulo: Atlas, 2010.

MEIRELLES, Hely Lopes. Direito administrativo brasileiro. 22. ed. São Paulo: Malheiros, 1997.

MESOMERCOSUL. Federalismo, Cooperativismo e Organização Social para o desenvolvimento. 2013. Disponível em: <http://www.mesomercosul.org.br/ >. Acesso em: 23 maio 2013.

REUNI. Programa de Apoio a Planos de Reestruturação e Expansão das Universidades Federais. Disponível em:

<http://reuni.mec.gov.br/index.php?option=com_content\&view=article\&id=100\&Itemid=81> . Acesso em: 20 maio 2013.

SILVA FILHO, Guerino Edécio da; CARVALHO, Eveline Barbosa Silva. A teoria do crescimento endógeno e o desenvolvimento endógeno regional: investigação das convergências em um cenário pós-Cepalino. Revista Econômica do Nordeste, Fortaleza, v. 32, número especial, p. 467-482, 2001.

SOLDI, Valdir et al. Projeto: Universidade Federal da Mesomercosul. Florianópolis: UFSC, 2007.

UFFS - Universidade Federal da Fronteira Sul. Estatuto. Ofício $\mathrm{n}^{\circ}$ 56/DESup/SESu/MEC/2010. Chapecó: UFFS, 2010.

Versão Preliminar do Plano de Desenvolvimento Institucional: PDI 2012-2016. Chapecó: UFFS, 2012. 